Please note! This is a self-archived version of the original article.

Huom! Tämä on rinnakkaistallenne.

To cite this Article / Käytä viittauksessa alkuperäistä lähdettä:

Uski, P., Pulkkinen, A., Hillman, L. \& Ellman, A. (2020) Issues on Introducing Model-Based Definition - Case of Manufacturing Ecosystem. Product Lifecycle Management Enabling Smart X: 17th IFIP WG 5.1 International Conference, PLM 2020. Springer, s. 604 - 617.

URL: https://doi.org/10.1007/978-3-030-62807-9 48 


\title{
Issues on Introducing Model-Based Definition - Case of Manufacturing Ecosystem
}

\author{
Pekka Uski ${ }^{10000-0001-6463-4596]}$, Antti Pulkkinen ${ }^{20000-0001-7442-5931],}$ \\ Lasse Hillman $^{3[0000-0002-9244-0542]}$, Asko Ellman ${ }^{40000-0002-2158-838 X]}$ \\ ${ }^{1}$ Etteplan Finland Oy, Juhana Herttuan Puistokatu 21, 20100 Turku, Finland \\ ${ }^{2}$ VTT Technical Research Centre of Finland Ltd, Visiokatu 4, 33720 Tampere, Finland \\ ${ }^{3}$ Tampere University of Applied Sciences, Kuntokatu 3, 33520 Tampere \\ ${ }^{4}$ Tampere University, Korkeakoulunkatu 6, 33720 Tampere
}

\begin{abstract}
The benefits of Model-Based Definition (MBD) are well known. Considering this there is a need to understand the reasons why MBD is utilized rarely in the manufacturing ecosystems of low volume, customized products. For studying MBD, manufacturing ecosystems and their mutual relations a literature study and a case study of manufacturing ecosystem were applied. It was noticed that there are differences between the maturities of digital product processes between the actors of the ecosystem, while MBD itself is a matter affecting the whole ecosystem. Investing in education and renewing, integrating and harmonizing processes, legacy data and software lower barriers towards adopting MBD. The motivation of the actors of an ecosystem has to ensure investments and commitment to change. The investment decisions require an ecosystem wide value definition and business case for each actor. The role of an actor within an ecosystem, how common or niche the utilized product and production technology is and the economic situation of a company appear to impact companies' willingness to change into MBD. Also, the motivation to adopt MBD depends on the amount of legacy data and the complexity of manufactured parts. Adopting PMI-data can increase the efficiency of manufacturing processes, such as quality control.
\end{abstract}

Keywords: Model-Based Definition, Model-Based Enterprise, MBD, MBE, Ecosystem, Manufacturing Ecosystem, PMI.

\section{Introduction}

Automotive, aerospace and military industries have been the forerunners in developing digital methods to seamless information flow from design engineering to production. For example, Toyota Motorsport announced already in 2004 that they were involved in a drawing-less project where the conception, manufacturing and inspection of engine components were carried out in a digital environment. In addition, Boeing was one of the first aircraft builders to utilize a complete digital definition in one of its aircrafts. [1]. 


\subsection{Objective of the article}

Manufacturing industry has not been an early adopter of digital thread. However, the practices of managing engineering data and used IT support for industries appear to be similar. Thus, the presentation and the use of information content can be a differentiating factor. In this paper, we study the reasons that prevent a manufacturing ecosystem from adopting digital methods integrating engineering design and manufacturing operations. The purpose of the paper is to increase understanding how digital functionality may come true in the ecosystem of the case.

Motivation. Our motivation to study and promote new ways to define and communicate product design comes from experience and practical cases. For example, an obvious need for the reconsideration of the means for product definition was noticed when a mechanical engineer was preparing manufacturing drawings for a certain steel construction project. The drawing sheet was finally a size of A0X5! One can ask how to utilize this size of a drawing in a manufacturing company as well as on a construction site. Of course, this leads to need to make more drawings in a smaller sheet due to part manufacturing processes. Furthermore, it is common to type annotations, including a bill of material (BOM), manually in the documents of large assemblies instead of getting them from the properties of a 3D model. Manual work and the redundancy of information causes a threat of inconsistencies and errors. Yet, 3D model is the mandatory source for 2D drawings, but manually typed several rows of BOM may cause mistyping and in a hurry, the checking of final documentation can be careless. Although it is inconvenient to study a large 3D PDF, one can zoom the view and to recognize details.

Even today, documents are the dominant means of communication in manufacturing and often files are a kind of digital twin of the paper-based documentation, but not the part or product itself. Therefore, the means of digital thread do exist at least in engineering design, but the manufacturing has not caught up in the potential of digital definition. We argue that MBD is one of the key enablers for the creation of a Digital Twin of a manufactured product.

Despite the obvious benefits of Model-based Definition (MBD), industrial companies still rarely utilized it [2]. Reasons for this are worth understanding. The ModelBased Definition is a basis for the wider term Model-Based Enterprise (MBE). In practise, MBE means that all or most of the functionalities of an enterprise rely on information in a form of a $3 \mathrm{D}$ model.

Research approach. We study the adoption of MBD in a manufacturing ecosystem with a triangulation of the findings of three sources. First, we carry out a literature study (chapter 2). Second, we interviewed a sample of case companies in a manufacturing ecosystem, and finally, we tested the benefits of MBD in a case study, replicating the actual operations of a subset of the ecosystem parties (chapter 3.). The research method is qualitative, and the aim is to provide answers to question, what are the factors preventing from and promoting for the adoption of MBD in a manufacturing ecosystem? As the research approach, we adopt critical realistic approach that was adopted by Fox 
[3] for revealing that the hype about Building Information Model (BIM) underplays many inter-related causal requirements. Although MBD and BIM are used in different technical contexts, they are conceptually similar and the critical realistic approach appears feasible.

\section{$2 \quad$ Literature review}

A reliable answer to the research question requires a definition of the topics that are the concepts related to MBD as well as the benefits and barriers of adopting MBD in industry. In addition, we define the role of product definition in a manufacturing ecosystem and the ecosystem itself.

\subsection{Product Definition in Engineering Design and Manufacturing}

Typically, a design engineer creates the product data with Computer Aided Design (CAD) and stores it in a product lifecycle management (PLM) system for the use of e.g. manufacturing operations. The data is comprised of models and documents, such as the drawings of parts, the structures of products and metadata. The drawings represent the characteristics of the part and structures represent the composition of a product, i.e. the bill of materials (BOM). Characteristics are geometric and alphanumeric data, such as dimensions, tolerances, surface qualities, material properties, etc.
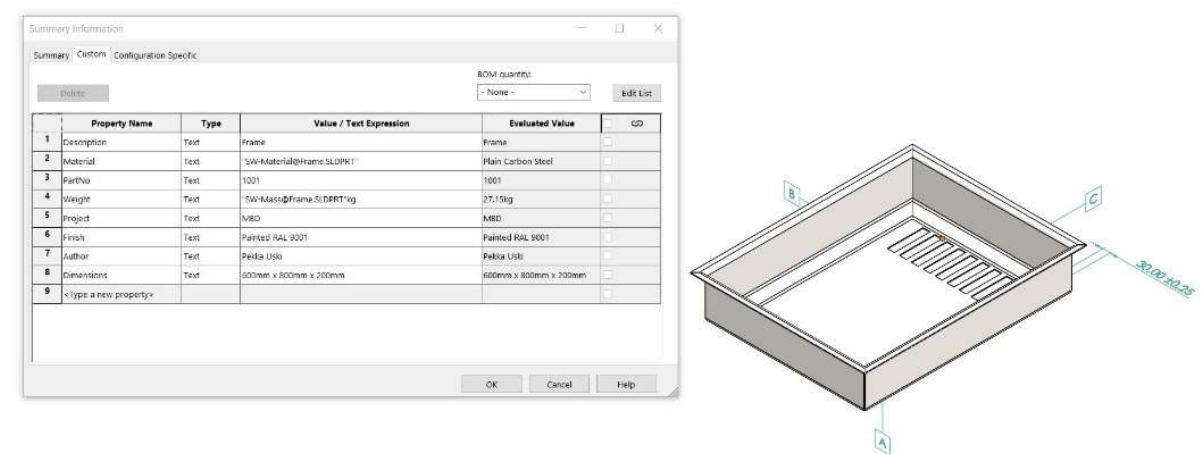

Fig. 1. Typical properties chart i.e. data card of 3D model. The model includes 3D annotations (datums A-C and dimensions).

Modern CAD software have possibilities to include part data, such as material, mass, dimensions, stock codes, color and engineer ID, to model's properties by filling the data card. The data card is usually included in PLM systems and so part or assembly properties can be inserted to a drawing's title block and bill of material (BOM). The properties chart includes 3D CAD's characteristics too and a separate PLM system may not always be needed (Fig 1). Utilizing the potential of the data card of 3D model varies in companies. Some use many possibilities of 3D and some trusts manual methods, even if 3D modelling is relevant part of product design and manufacturing. 


\subsection{Model-Based Definition}

Model-Based Definition (MBD) [1] can serve as an integrated presentation of a part and replace the datasets of models and drawings [4, 5]. Thus, MBD embraces the idea of a "single source of truth", by combining the different and potentially inconsistent sources of information [6]. Model-Based Definition (MBD) is an annotated 3D model and its associated data elements that fully define the product. The MBD includes all tolerances, dimensions, surface quality, material information as well as process specifications annotations that are needed for downstream users in a company and its networks. A MBD may include a Bill of Material (BOM) and product life-cycle management attributes, when it constitutes an authoritative, single source of master, product definition data completely without 2D drawings. [2].

Quintana [1] points out that Model-Based Definition means the 3D product model is the most appropriate vehicle for the delivery of all the detailed product information necessary for downstream organizations to perform their portion of the product delivery cycle. MBD is a thing, a digital representation (artefact) of a physical object or system and all its attributes is used to communicate information within various MBx activities in model-based enterprise [7]. Ruemler et al. [7] means by MBx model-based manufacturing (MBm), model-based sustainment (MBs) and any other model-based activities $(\mathrm{MBx})$ are categories of activity within the model-based enterprise. Adamski [8] defines Model-based Definition (MBD) as a process that allows the design team to input all their information into the $3 \mathrm{D}$ model, thus eliminating the need to create a drawing.

Product and Manufacturing Information. According to Herron [9] Product and Manufacturing Information (PMI) conveys non-geometric attributes in 3D Computer Aided Design / Manufacturing / Inspection / Engineering (CAx) systems necessary for manufacturing product components. PMI may include Geometric Dimensions \& Tolerances (GD\&T), 3D annotation (text) and dimensions, surface finish, and material specifications. CAx application literature may also refer to PMI synonymously with Geometric Dimensions and Tolerances (GD\&T) or Functional Tolerancing and Annotation (FT\&A).

Model-based Enterprise. Model-based Enterprise (MBE) is a fully integrated and collaborative environment founded on 3D Model-based product definition constructed and shared across the enterprise to enable the deployment of products from a concept through delivery [10]. MBE is an environment, e.g. an organization that has transformed itself to leverage model-based information in its various activities and decisionmaking processes [11]. 


\subsection{The benefits of MBD}

Model-Based Definition speeds the product ramp-up and lowers quality defects [1]. Apparently, there are separate mechanisms for this, as some of effects caused by MBD associate to information management and processes in general, while other effects are distinct benefits that appear in the separate activities of process. The essential purpose of MBD is to accelerate and to improve communication between the parties of product development. According to the author's experience, every product development and engineering project has difficulties due to deficiencies of communication. The singlesource principle is the key general benefit of the MBD [9], because the same 3D model can be utilized in the several process phases of an enterprise. Another general aspect of utilizing the MBD is that, 2D drawings can be avoided, which means it is not anymore needed to control whether there are correct paper-revisions in a production or not. This presumes the shared source of information and persistent processes of MBE.

Automatic toolpath generation is a distinct, but repeatedly gained benefit enabled by MBD. The use of MBD datasets can be useful also in quality control as the geometry and associated attributes, such as dimensions, geometric tolerances, datums and surface qualities, are part of a MBD. Unlike Quintana et al. [1] noticed, path planning for Coordinate Measuring Machine (CMM) based on part geometry, can incorporate the use of tolerance data. We noticed this during the measuring test that we describe later in this article. Zhu [12] introduced that MBD enables the intelligent manufacturing of parts. This is possible through a feature machining and Coordinate Measuring Machine (CMM) control technologies.

\subsection{Barriers of MBD}

According to Ruemler et al. [7], large capital investment, lack of business pulls, and legacy designs are the biggest barriers of utilizing MBD and MBE. The study revealed that the lack of workforce skilled in MBD or the lack of training opportunities were less regarded issues. All these are general barriers against the use of MBD. Quintana et al. [1] categorized the barriers towards utilizing the MBD into three main categories: technical issues, process issues and legal issues [1].

Technical issues. Problems may occur when there is different software in delivering than in receiving systems. Consequently, a receiving system cannot open the files. Difficulties may come also when the maturity level of MBE is different in delivering and receiving organizations. For example, a customer sends separate 3D STEP files to the sheet metal manufacturing subcontractor that can utilize only 2D DXF files. In that case, the customer may need to make traditional, redundant 2D drawings, including all necessary dimensions, tolerances and annotations. The 2D drawings will be saved as PDF and/or DXF/DWG files and the subcontractor often prints them on paper. Technical issues are distinct barriers preventing the efficient use of MBD, even though they may appear repeatedly. 
Process issues. Data accessibility and visualization can be a distinct, key issue preventing the use of MBD, because most downstream users (including suppliers and customers) do not have access to CAD software. Therefore, visualization tools that enable the users to access and present the MBD datasets are vital. Data content is another process issue, because downstream users need to be confident that the MBD datasets will carry the core of a drawing and the required management elements.

The single sourcing and use of data are important for manufacturing operations and production planning, e.g. computer aided manufacturing. Users need that an MBD dataset is in machine-readable form, a representation of product definition. This approach can ensure the seamless single source of product definition and minimize unnecessary, distinct errors due to human intervention, e.g. in off-line programming of toolpaths.

Version management means that an appropriate method must be available in order to manage and record revisions of MBD datasets. Data security is another issue, because a mechanism that incorporates security features (confidentiality, authentication, integrity and non-repudiation) when accessing, exchanging and interacting with MBD datasets will be required. Both of the issues appear to be general barriers against MBD.

Data retention is another general issue against the use of MBD, because usually only 2D data is stored and used for legal or business purposes. The distinct examples of this are:

- A request for quote

- Validation and release

- Manufacturing

- Inspection

- Certification

- Engineering change management (ECM)

- Long-term storage

Traditionally, drawings are considered as the controlling contract document with customers and suppliers. Drawings, electronic, printed or microfilmed, are the usual medium to safely and securely preserved the product definition, which allows for product maintenance and data reuse.

Legal issues. Governments control very strictly some products and industries such as medical, military, construction, aircraft and vehicle industries. All products and processes of them, need to be done very properly. Herron [9] has found five main barriers to overcome on the road to adopting MBE:

1. Decision makers need more information about Model-Based Engineering

2. Holes appear in the technology tapestry of Model-Based Enterprise.

3. Standards do not address large-scale assembly integration into MBE.

4. Agreement on authoritative sources needs to be determined.

5. Change is hard, that causes often change resistance.

All the legal issues cause a general barrier against the adoption of MBD, even though they may appear distinct issues alone. 
Summary of barriers. For a company, transition to MBD is an investment and each investment must pay off in a form or another. Change from traditional product definition to MBD is a project, which must result with a higher benefit than the investment. Thus, the business case for a MBD project is necessary.

A company has usually invested in the legacy processes and archives of designs in files and models. The legacy product data is an illiquid asset and a company usually cannot convert it easily into another format. Getting rid of or the re-design of a large set of designs into a new format may not be appealing. The amount of legacy data can be large in a company that has to manage it along with new data. Some companies have stored legacy data to different databases or systems than the new data. It may not a viable option to combine old drawings and 3D models to a new system. Eventually, the size of the new database can be much larger than the legacy data.

When adopting MBD an organisation is not only changing technology but also making changes in engineering design and manufacturing engineering processes. If the technology and the processes do not comply with each other, it may be difficult to motivate the change. However, the technology has to provide seamless digital thread for computer-integrated processes. The business and legal processes contain distinct issues that as a whole cause a barrier against the utilization of MBD.

\subsection{Product definition in an Ecosystem}

A single enterprise is hardly responsible of both design and manufacturing of all the parts and product definition is a matter of inter-organizational communication. Organizations must exchange product definition, either in a form of MBD or traditional document-oriented definition, between engineering and manufacturing organizations.

Digital Extended Enterprise. A whole supply network may form a digital extended enterprise, if the given conditions on e.g. business development, processes, metrics, and information sharing are met [13]. The interconnected infrastructure, environment, and methodology (process, methods, and tools) used to store, access, analyze, and visualize evolving systems' data and models to address the needs of the stakeholders [14]. Developing a digital extended enterprise requires development activities in many fields and product definition is one of them. However, the development should occur with a balanced manner, because the key development areas are interrelated. [15]. The utilization of a digital extended enterprise can lead to remarkable improvements for example in the reliability of suppliers' deliveries and quality. The concept of single sourcing is essential in the digital extended enterprise, because in it the up-to-date digital definition is shared, version management enhanced and access to consistent product definition ensured throughout the extended enterprise [13].

Ecosystems. An ecosystem is always a unique concept, which has a unique set of actors and interactions [16]. The ecosystem has borders and each actor has a certain role, which may differ from roles in other ecosystems. The borders can be set by geographical scope, by temporal scale, by permeability, as well by types of flows (material, 
knowledge, value) [16]. As well as the ecosystem, have actor's common target and purpose to act to serve the whole ecosystems benefit. Typically, the manufacturing ecosystem, which is one type of business ecosystems, consists of a keystone, a niche, a commodity and a physical dominator (PD) [17]. The keystone is the company, which dominates the value of the ecosystem. It also protects the ecosystem against other ecosystems, and it provides rules and standards for other actors in the ecosystem. Niche is the actor that has special skills and technology. Physical dominator occupies a wide range of technology and services in the ecosystem. However, the physical dominator results a low level of innovation. The commodity competes with price and volumes by producing components with a large series.

Collaborative networks as well as an outsourcing, according to the standard ISO 44001 [18] belong also to business relationships. They have similarities with business ecosystems like common target with each actor but also differences. The collaborative network and the outsourcing may function between two companies only. The other company sells products and/or services to the other and each company develop its business individually. Each actor in a business ecosystem needs to develop business on the ecosystems' point of view.

\section{A Case of a product definition in the manufacturing ecosystem}

Several manufacturing companies and three research institutes are carrying out a joint development and research project under the title "Intelligent Manufacturing Ecosystem" (IME) during 2019-2020. The companies presented in this chapter are part of the project consortium, but not the whole consortium. The project IME has three themes focusing on intelligent materials, engineering and manufacturing, and ecosystem.

Table 1. Characteristics of case companies (values from 2018)

\begin{tabular}{|c|c|c|c|c|c|}
\hline Position & $\begin{array}{l}\text { Turnover } \\
\text { (M€) }\end{array}$ & $\begin{array}{l}\text { Result } \\
\text { / (M€) }\end{array}$ & Specialization & $\begin{array}{l}\text { Person- } \\
\text { nel }\end{array}$ & $\begin{array}{l}\text { Actor / } \\
\text { role }\end{array}$ \\
\hline Customer & 1000 & 155.6 & $\begin{array}{l}\text { Dedicated mobile } \\
\text { machinery }\end{array}$ & 2009 & Keystone \\
\hline Supplier A & 15.7 & 1.8 & $\begin{array}{l}\text { Bearing sleeves, } \\
\text { material expert }\end{array}$ & 85 & Niche \\
\hline Supplier B & 12.5 & 0 & ETO Gears & 62 & Niche \\
\hline Supplier C & 9.4 & 0 & $\begin{array}{l}\text { Subcontractor ma- } \\
\text { chine shop }\end{array}$ & 50 & $\mathrm{PD}$ \\
\hline Supplier D & 7.6 & 0.3 & $\begin{array}{l}\text { Subcontractor ma- } \\
\text { chine shop }\end{array}$ & 40 & PD \\
\hline Inspector & & & Measuring & & Niche \\
\hline
\end{tabular}

This case study is part of work package the integration of engineering design and manufacturing and it focuses on five industrial companies of the IME (see Table 1). 
One of them was the customer company for the other four companies, i.e. suppliers. The customer has outsourced part manufacturing and the suppliers deliver components and subassemblies that the customer designs and assembles in its products. In the case, the customer acts as a keystone, the suppliers A and B can be described as a niche and the suppliers $\mathrm{C}$ and $\mathrm{D}$ are typical physical dominators. Albeit, the nature of the ecosystem in this research is kind of niche itself and the size of product series is relatively small, the Suppliers C and D represent a commodity in this ecosystem and context.

In addition, the sixth organization acted as a niche actor for the manufacturing ecosystem by replicating the measurement operations in the laboratory of the university (Inspector). The laboratory has the digitalized, integrated measurement facilities, such as similar CAx environment than the Customer and coordinate measurement machine (CMM). During the case, the Inspector made measurement tests to find out how feasible the PMI-model is when measuring a part without engineering drawings.

\subsection{The ecosystem members}

The Customer - a keystone. The customer company of the ecosystem is manufacturing mobile machinery for a dedicated, niche purpose. The international corporation, the customer is part of, is investing $18 \mathrm{M} €$ on developing an R\&D center in Finland. The company has recognized that it must update the technology of the key module of the product offering and at the same time modernize the factory that produces the module. While the factory is undergoing a large modernization and automation project, also the processes and management of product definition, production, supply chain collaboration and information exchange must be re-considered. The objective is to enhance information and material flow, radically increase agility and to reduce throughput time in both product development and in production processes. Simultaneously, the company must maintain or improve the high level of quality. The role of networks and manufacturing ecosystems is critical in the achieving of the objective, while the company is solving many issues on production, engineering and collaboration. For all this, the company has launched a manufacturing ecosystem project with selected supplier companies, IT-vendors, consultants and researchers from different institutions.

In the project, the customer company is aiming at Model-Based Definition internally and in the ecosystem where it is collaborating with its key suppliers. However, the company must recognize how far the suppliers are able to go with MBD. In the beginning of the ecosystem project, the company recognized that drawings were still a master of product definition for it even though drawings always accompany a part model in the native format of the CAD system (NX by Siemens). The intent of the company is to change this so that a model will be a master file, sometimes accompanied by a drawing. Along with this, the company will take into use MBD and derive drawings when needed. In the beginning most of the suppliers relied solely on part drawings, while some received the geometry in STEP- or JT-files. The aim is to study the potential of sharing MBD files with the selected suppliers. 
Supplier A - niche. The supplier A has also a long history of manufacturing machined products as parts for the machinery. Typically, the parts are sleeve bearings for large installations in demanding conditions. On top of only machining parts, the company also casts the blanks of bronze for products. The material is mostly re-cycled from outside and within the company. Typically, the parts are axially symmetric, and the geometries are quite simple, and invariant. The number of customers is large and stable, when the company's ability to deliver bearings and gaskets with special alloys at a short notice is an asset. In addition, material management is a competitive asset for the company.

The product documentation is typically in the format of part drawings, stored either in paper archives or in PDF files. The company did not indicate a need to change the way of managing product definition, because the geometries of products are rather simple and persistent. In addition, changes in the way of work for just one customer do not pay off in the case of many customers. Instead, automation and managing the flow of material and the management of materials in general may be more appealing investments for the company.

Supplier B - niche. The company manufactures components for gear installations with high performance requirements. An asset for the company is the ability manufacture specialized gears with high precision and to sustain the high quality of products. Therefore, the geometries of the parts do not follow standardized modules of part geometries. Therefore, the company has specialized grinding tools for the special gear geometries. When considering the routing of the parts and products, the management recognized that the company would benefit from the MBD only in the very first stages of production or in the final inspection of parts, which sums up only about $20 \%$ of the whole production. Thus, investing in MBD is not an intention of the company and the focus is on enhancing the production management and flow of production. None of the suppliers had already a dedicated manufacturing execution system, but supplier B was implementing a system for manufacturing operations planning, simulation and management.

Supplier C - physical dominator. The case company has a history of 50 years of part manufacturing with more than 30 machining systems such as $\mathrm{NC}$ controlled lathes and machining centers, robots for tool and part exchange as well as a dumbwaiter and a CMM. The clientele is quite large, comprising of both many national and some international customers, who deliver part documents in PDF-files and sometimes the geometry of parts in native CAD or STEP format. The products are prismatic and axially symmetrical machined parts and a team of few experts does the toolpath programming of parts. The variations of parts and part geometries exhibit in complex part documentation. The flexibility and the expertise of the CAM team are assets for the company. Typically, a new, complex part geometry takes one day of offline programming.

The company has automated part and tool exchange to certain extent, but due to the small series of products, full automation is not feasible. A typical set size, the company reported in an interview is approximately 40 pieces. A separate unit does the inspection 
of machining and the set of tools such as CMM system deliver measurement reports in PDF format. The labelling of products and document management is manual.

An asset for the company is the expertise in heavy machining and the continuous modernization of equipment. The company is aiming at streamlining the computer aided manufacturing of parts. For this purpose, the company has been introducing the same NX CAM as some of the main customers of the company have already. Therefore, the company expects that the use of MBD is going to replace part drawings, in some cases. The company may also invest in managing the data from quality assurance, i.e. the CMM data, so that the customers investing in MBD would be served better than drawing oriented customers.

Supplier D - physical dominator. The manufacturing company focuses on subcontracting machined parts for a limited set of customers. The company delivers more than $75 \%$ of production value to two main customer companies. Typically, the toolpath generation relies on part geometry in STEP-file, and the drawings indicating the tolerances and surface qualities of the parts. The company makes part inspection with CMM's, but statistical process control is not possible due to a small series (less than 40) of production.

One of the assets of the company is the marking of the parts so that the traceability of the parts is possible. In general, the company is rather development oriented, and it is investing in MBD as well as in automation.

Inspector-Niche. Tampere University of Applied Sciences (Tampere UAS) had a pilot project in Intelligent Manufacturing Ecosystem, with supplier and its customer. The target was to find out the benefits of using PMI data with coordinate measuring machine comparing measuring by traditional way.

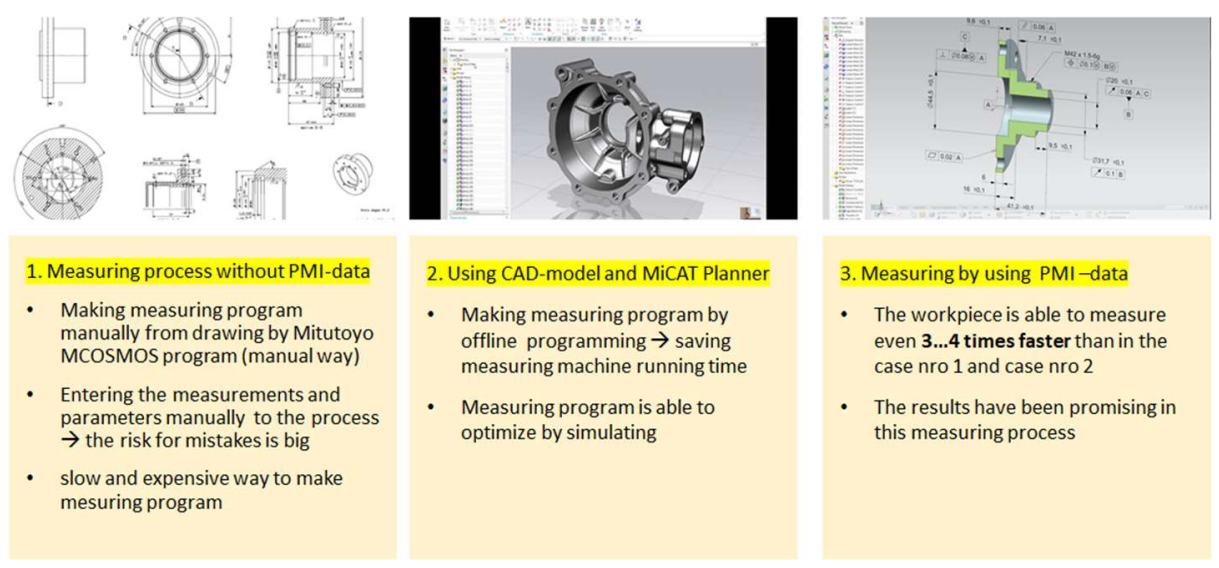

Fig. 2. Three ways to measure the workpiece by using coordinate measuring machine (CMM).

The laboratory set up resembled the actual situation within Supplier D, but the Inspector utilized the MBD instead of traditional part definition in the measurement operations. 
Thus, the Inspector's laboratory tests provided a comparable empiric evidence on the utilization of different forms of product definition.

The empiric research brought forth several direct benefits:

- Measuring by using PMI-data is 3...4 times faster than in traditional way

- The more features there are to measure, the more evident the difference between the traditional way and using PMI-data becomes

- Applying PMI, improves the lead time of production

- The benefit is bigger, if production batch is small

- Measuring process with PMI-data is simpler, so it is easier to teach more people in the production to use measuring machine

One may regard the benefits above as distinct benefits that Supplier D can gain within the quality control operations of the company. Likewise, the supplier $\mathrm{C}$ might have similar benefits in quality control, although the replication did not include data from it.

\section{$4 \quad$ Results and discussions}

In this article, we have studied several barriers and issues in introducing model-based product definition with a literature research as well as by studying the case of manufacturing ecosystem. On top of the qualitative assessment of literature and material from interviews, researchers conducted an empiric study replicating the measurement operations of a company. Some of the results of the empiric study are quantitative.

It is noteworthy that companies can solve many of the technical challenges and MBD is a feasible option to represent product information within a manufacturing ecosystem. Moreover, MBD is a specific topic for a manufacturing ecosystem, because its' members add value to the ecosystem with different means. For example, single sourcing is a mutual, general interest that can benefit the whole ecosystem, but often with an indirect manner.

A decisive challenge for the adoption of MBD in an ecosystem is the community nature of MBD as it is a means of communication and, thus, requires that both sides of the communication, which are the maker and the users of documentation, agree upon the means. Within the challenge, a general issue that both Ruemler et al. [6] as well as we acknowledged is the reasoning of business investment in MBD. In an ecosystem, the mutual, comprehensive model of ecosystem business case is needed in order to balance the investment and value added. There, the concept of dispositions by Andreasen $\&$ Olesen [19] may a viable option to represent the relations between the members of manufacturing ecosystems.

The second issue to acknowledge is the co-existence and the need of several ecosystems. Along with business ecosystem there is a need for knowledge ecosystem that will enhance the knowledge on MBD. For example, to a manufacturing service provider or a supplier the potential of MBD and the ways of presenting e.g. geometric tolerances with MBD require often the introduction of new knowledge. Investing in education on utilizing Model-Based Definition [20] can lower the barrier to adopt new methods. 
Also, the versions of software brands support certain standards of MBD representation while other versions do not.

The software and the related standards form an innovation ecosystem that runs according to its own rules. Being aware and solving the issues of interoperability requires knowledge on the rules. In practise, companies can avoid the incompatibility issues between systems and software by using similar systems or file transferring formats. Nowadays several 3D CAD software include smart tools for file transferring and Model-Based Definition. Standards, such as ISO 16792 and ASME Y14.41, have been supporting digital product definition for a long time.

Revision management, data retention, data accessibility and visualization all can be managed by modern systems, but they require the adoption of mutually operated processes. In a business ecosystem the setting of the rules for digitally enhanced processes is another topic worth noticing. When considering manufacturing ecosystems as well as supply chain networks, to be able to act in digital process, it is fundamentally important for all actors in ecosystems and networks to have similar abilities of digital processes. In addition, all actors must have high motivation to change way to work. For a single company, adopting MBD is a long-term investment and therefore requires strategic collaboration between the members of a manufacturing ecosystem. Like we have noticed in the case, Suppliers C \& D have challenges in business profit as niche actors. However, they are motivated to develop processes, such as MBD, and consequently they are investing in the new way to work. However, the dominant actors, such as Suppliers $\mathrm{A}$ and $\mathrm{D}$, find the mentioned barriers, such as lack of recognized benefit and legacy data, as inhibitors for adopting MBD. The empirical study proved there are leapfrog benefits using PMI-data in measurement process. To be able to prove benefits can be found in whole operations processes product lifecycle, more research need to be done.

Acknowledgements. The research organizations have received financial support from Business Finland for the project IME and the authors of the paper acknowledge the support. Authors are grateful for the collaboration with the companies.

\section{References}

1. Quintana, V., Rivest, L., Pellerin, R., Venne, F., Kheddouci, F.: Will Model-based Definition replace engineering drawings throughout the product lifecycle? A global perspective from aerospace industry. Computers in Industry 61, 497-508 (2010).

2. Action-Engineering, 3D Model Based Definition. Available at: https://www.action-engineering.com/dictionary/\#3d_model\%20based\%20definition, (2019a), (accessed 25 November 2019).

3. Fox, S. Getting real about BIM: Critical realist descriptions as an alternative to the naïve framing and multiple fallacies of hype. International Journal of Managing Projects in Business, Volume 7, Issue 3, 27 May 2014, Pages 405-422, https://doi.org/10.1108/IJMPB-122013-0073 
4. Camba, J, Contero, M., Johnson, M., Company, P. Extended 3D annotations as a new mechanism to explicitly communicate geometric design intent and increase CAD model reusability. Computer-Aided Design 57, 61-73, (2014).

5. Alemanni, M., Destefanis, F., Vezzetti, E. Model-based definition design in the product lifecycle management scenario. International Journal of Advanced Manufacturing Technology 52(1-4), 1-14, (2011).

6. Schuh, G., Rudolf, S., Riesener, M., Design for Industrie 4.0. In: International design conference-Design 2016, Dubrovnik, 2016, (2016).

7. Ruemler, S.P., Zimmerman, K.E., Hartman, N.W., et al., Promoting model-based definition to establish a complete product definition. Journal of Manufacturing Science and Engineering, Transactions of the ASME 139(5). American Society of Mechanical Engineers (ASME). DOI: 10.1115/1.4034625, (2017).

8. Adamski, W., Adjustment and implementation of CAD/CAM systems being used in Polish aviation industry. Journal of Machine Engineering 10(3), 37-47, (2010).

9. Herron, J., Re-Use Your CAD. The Model-Based Handbook. CreateSpace Independent Publishing Platform, (2013).

10. Action-Engineering, 3D Model Based Enterprise. Available at: https://www.action-engineering.com/dictionary/\#3d_model\%20based\%20enterprise, (2019b), (accessed 25.11.2019).

11. Hartman, N.W., Establishing a lexicon for the Model-Based Enterprise. West Lafayette, (2017).

12. Zhu, W., Bricogne, M., Durupt, A., et al., Implementations of Model Based Definition and Product Lifecycle Management Technologies: a Case Study in Chinese Aeronautical Industry. IFAC-PapersOnLine 49(12). Elsevier B.V.: 485-490. DOI: 10.1016/j.ifacol.2016.07.664, (2016)

13. Pulkkinen, A., Anttila, J-P., Leino, S-P., Assessing the maturity and benefits of digital extended enterprise. Procedia Manufacturing, Volume 38, 2019, Pages 1417-1426, p. 10., (2019). https://doi.org/10.1016/j.promfg.2020.01.146

14. Action-Engineering, Digital Engineering Ecosystem. Available at: https://www.action-engineering.com/dictionary/\#digital_engineering\%20ecosystem, (2019c), (accessed 25.11.2019).

15. Pulkkinen, A., Vainio, V., Leino, S.-P., Anttila, J.-P., Modelling of Digital Extended Enterprise, In: 20th International Dependency and Structure Modeling Conference, DSM 2018Trieste, Italy. (2018).

16. Valkokari, K.: Business, Innovation, and Knowledge Ecosystems: How They Differ and How to Survive and Thrive within Them. Technology Innovation Management Review 5(8), 17-24 (2015).

17. Paulus-Rohmer, D., Schatton, H., Bauernhansl, T.: Ecosystems, strategy and business models in the age of digitization - How the manufacturing industry is going to change its logic. In: Editor, F., Editor, S. (eds.) $49^{\text {th }}$ CIRP CONFERENCE on Manufacturing Systems (CIRPCMS 2016) 2016, vol. 57, pp. 8-13. Elsevier B.V., (2016).

18. ISO 44001:2017 Collaborative business relationship management systems - Requirements and framework. 2017-03, https://www.iso.org/standard/72798.html (accessed 29.2.2020).

19. Andreasen, M. M., Olesen, J. The Concept of Dispositions. Journal of Engineering Design. Volume 1, Issue 1, 1990 (published online 31.1.2007, Taylor \& Francis Online), pp. 17-36 https://doi.org/10.1080/09544829008901640.

20. Garland, N., Wade, R., Glithro, R., et al. Model Based Definition: Finally, the engineering drawing killer? In: International conference on engineering and product design education, Strathclyde, 2019. University of Strathclyde, (2019). 